\title{
Accuracy of comparing bone quality to chocolate bars for patient information purposes: observational study
}

\author{
Phil Jones, Sarah Jones, Debbie Stone
}

\section{Bronglais General Hospital, Aberystwyth SY23 1ER \\ Correspondence to: $\mathrm{P}$ Jones phil.jones@ceredigion-tr.wales. nhs.uk}

BMJ 2007;335:1285-7 doi:10.1136/bmj.39413.798472.BE

\section{ABSTRACT}

Objective To test whether standard information for patients using Crunchie and Aero chocolate bars to explain bone health and risk of fracture is robust.

Design Observational study.

Setting Domestic kitchen in rural west Wales.

Participants 10 Crunchie bars and 10 Aero bars.

Main outcome measure Fracture after falls from varying heights.

Results Both Crunchie and Aero bars exhibited the same $T$ and $Z$ scores for bone density. Crunchie bars had a lower chocolate mass index than the Aero bars. Crunchie bars are more liable to fracture.

Conclusions Using Crunchie and Aero chocolate bars to explain bone structure to patients may be visually attractive but oversimplifies the situation.

\section{INTRODUCTION}

It is important that information provided to patients as part of their treatment should be comprehensive and accurate. Within our area of practice relating to osteoporosis and fragility fracture we have noticed a tendency to compare normal, healthy bone to the finely honeycombed structure of a Crunchie (Cadbury Trebor Bassett; Bournville, Birmingham) chocolate bar and to compare abnormal, osteoporotic bone to the coarser structure of an Aero (Nestle UK; York) bar (fig 1). ${ }^{1}$ Although this explanation is readily appreciated by patients and clinicians it struck us that the comparison may not be completely valid as no work has been published on the fracture potential of each bar. This might mean that with best intentions we are advising patients to aspire to a bone structure that is actually more liable to fracture. To enable us to provide accurate data to our patients we studied the fracture risk for each chocolate bar.

\section{METHODS}

We randomly purchased 20 chocolate bars (10 Crunchie and 10 Aero) from a reputable high street confectioner; the number of bars was limited by research funds and our rural environment. Each bar was measured to provide information on height
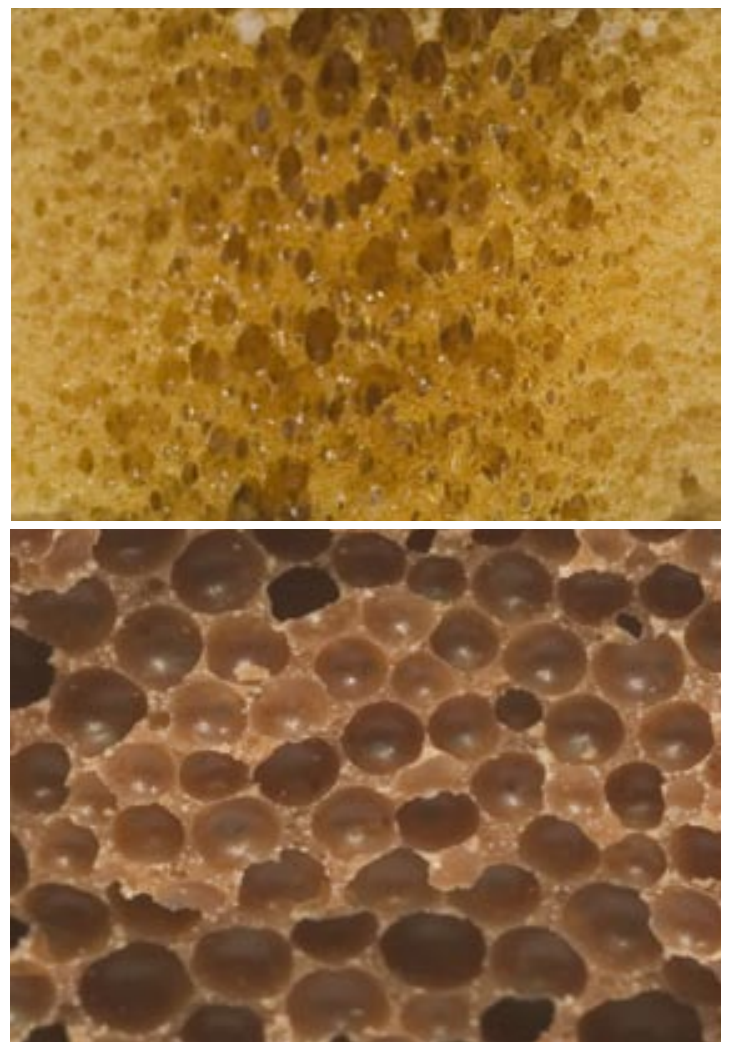

Fig 1 | Cross section of Crunchie (top) and Aero (bottom) chocolate bars

(defined as the longest dimension of the bar, in metres) and mass (determined in kilograms). The composition of the bar was determined through reference to the packaging. We could ascertain no data on other fracture risks. The tests were completed in a controlled environment and the flooring was standard $33 \times 33 \mathrm{~cm}$ ceramic kitchen floor tiles with average grouting. This environment was chosen as being representative of the home environment, where many fractures occur.

The end point of the study was fracture. Firstly, we allowed each bar to topple from its standing height in the centre of a tile. We then dropped each bar horizontally on to the centre of the tile from increasing heights until fracture, defined as a break in the cortex; 
we did not regard mild deformity as a fracture. The tests were carried out at a temperature of $22^{\circ} \mathrm{C}$ after the bars had had eight hours to reach a steady state temperature. We used a bone densitometer (Discovery-C; Hologic, Bedford, MA) to carry out dual energy $\mathrm{x}$ ray absorptiometry (whole body) on one Aero and one Crunchie, with bone mineral density being used as a surrogate for measuring chocolate density. Height was measured with a tape measure (Olympia ( $5 \mathrm{~m} / 16 \mathrm{ft}$ ) Power Return Tape; Olympia (UK); Reading, Berks). We chose a Kaplan-Meier "fracture free" survival curve as the best means of analysing the data obtained.

\section{RESULTS}

The table provides comparative data for Crunchie and Aero chocolate bars. All bars had the same dimensions (to within the accuracy of our measure). No bars fractured in falls from a standing height. A Kaplan-Meier survival curve shows the occurrence of fractures according to heights (fig 2). Figures 3-5 show the range of fractures.

\section{DISCUSSION}

Using Crunchie and Aero chocolate bars to explain bone structure and fracture risk to patients may be visually attractive but oversimplifies the situation. Our findings must be interpreted with some caution as we used a small number of participants and the falls were not low trauma-that is, standing height or less. To date a reliable population database for chocolate densities has not been established and we acknowledge that our reference population is somewhat subjective; there may be scope for further research in this area, including risk of fracture over 10 years. Our findings, however, clearly show that despite the apparently more robust structure of a Crunchie it is more likely to fracture than an Aero.

It is generally recognised that bone strength is a reflection of bone density and bone quality and therefore the explanation for our incidence of fracture is likely to be multifactorial. It may include differences in chocolate mass index (2.16 for Crunchie $v 2.76$ for Aero), and the higher protein content of the Aero is likely to provide more elastic stress properties than that of the Crunchie.

Characteristics of Crunchie and Aero chocolate bars

\begin{tabular}{lcc} 
Characteristic & Crunchie & Aero \\
Height $(\mathrm{m})$ & 0.136 & 0.129 \\
\hline Weight $(\mathrm{kg})$ & 0.04 & 0.046 \\
\hline Chocolate mass index $(\mathrm{kg} / \mathrm{m} 2)$ & 2.16 & 2.76 \\
\hline Content: & & 3.0 \\
\hline Protein $(\mathrm{g})$ & 1.6 & 27.0 \\
\hline Carbohydrate $(\mathrm{g})$ & 27.8 & 14.6 \\
\hline Fat $(\mathrm{g})$ & 7.6 & 0.4 \\
\hline Fibre $(\mathrm{g})$ & No data & Trace \\
\hline Sodium $(\mathrm{g})$ & No data & 0.1 \\
\hline Salt equivalent $(\mathrm{g})$ & No data & No data \\
\hline Calcium $(\mathrm{g})$ & No data & No data \\
\hline Collagen $(\mathrm{g})$ & No data & -8.8 \\
\hline Tscoret & -9.5 & -8.8 \\
\hline Zscoreł & -9.5 &
\end{tabular}

$T$ and $Z$ scores are referenced to 50 year old woman.

†Number of standard deviations above (or below) mean for peak bone mineral density score.

¥Age and sex matched number of standard deviations above (or below) the mean bone mineral density score.

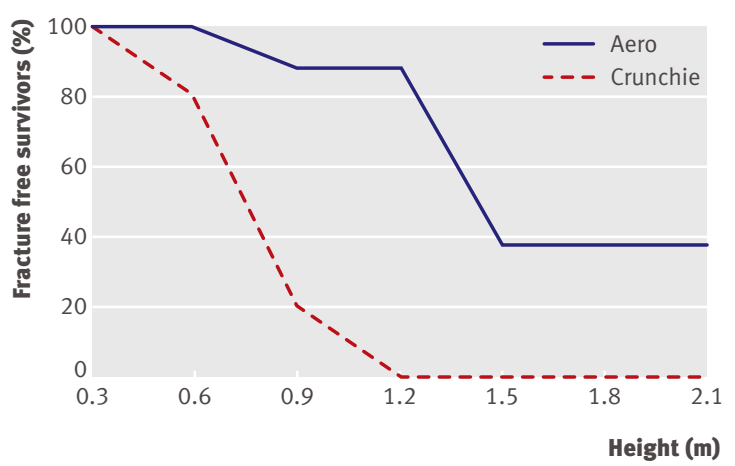

Fig 2 | Fracture free survival curves for Crunchie and Aero chocolate bars

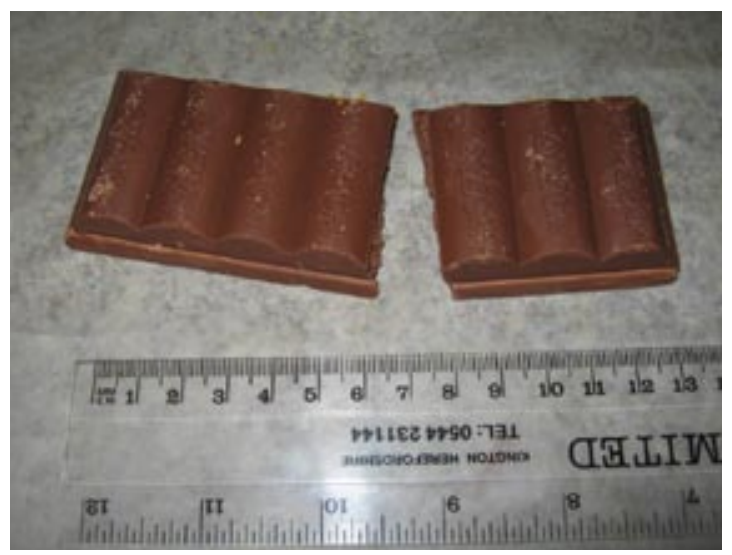

Fig 3 | Simple, complete fracture at interchunkal area of Aero chocolate bar, the only fracture seen in the Aero group

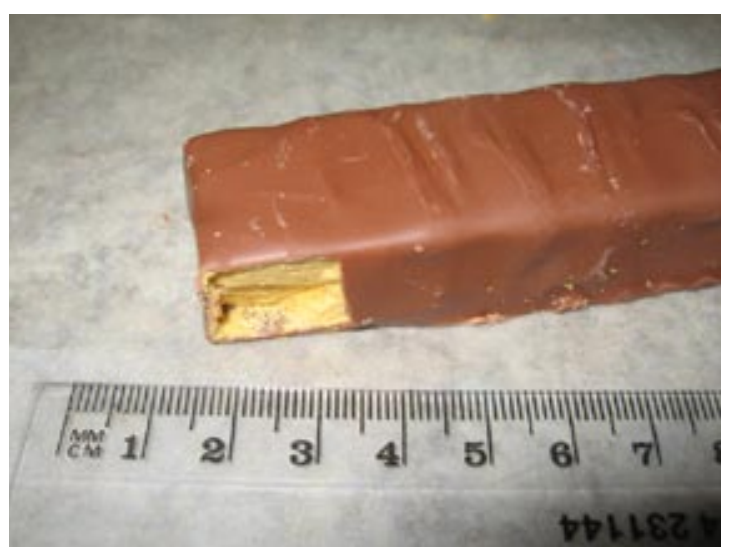

Fig 4 | Splinter fracture in Crunchie chocolate bar

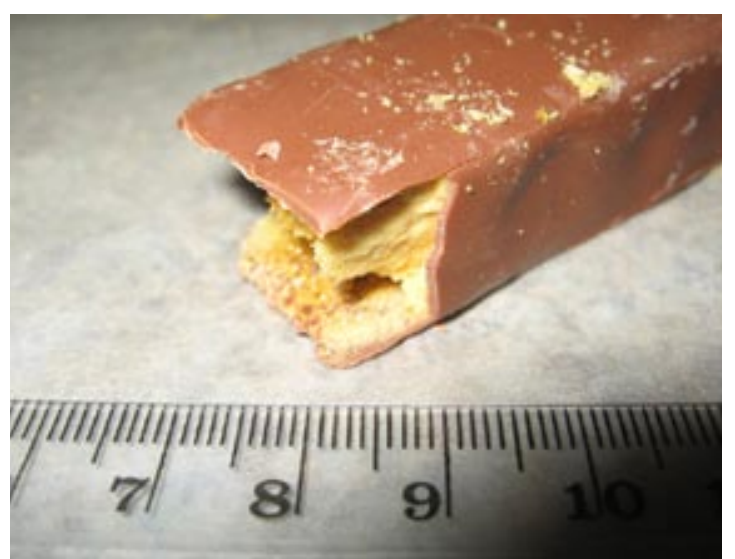

Fig 5 | "Blow-out" fracture at higher fall heights in Crunchie chocolate bar 


\section{WHAT IS ALREADY KNOWN ON THIS TOPIC}

Increase in bone porosity is implicated in increased fracture risk in vivo but is not the only determinant

The use of confectionary visual aids in patient education is widespread among health professionals to convey fracture risk to patients

\section{WHAT THIS STUDY ADDS}

Fracture risk is not wholly determined by dual $x$ ray absorptiometry, and a full and rigorous fracture risk assessment is required for both chocolate bars and, more importantly, patients

Our data provide evidence of the disparity between chocolate density and fracture rates. The use of Crunchie and Aero bars to explain bone health and fracture risk to patients, although palatable, is not justified. In practical terms we believe that the findings should contribute to the provision of improved patient information and education by enlightened healthcare professionals. The study serves to remind clinicians that both chocolate density and bone mineral density form but one component of fracture risk. The accurate assessment of fracture risk should ideally take into account other measurable indices that contribute to fracture risk in addition to that provided by chocolate density and bone mineral density.

We thank Phil Stone for measuring the bars and Diane Hughes for carrying out the dual $x$ ray absorptiometry.

Contributors: PJ, SJ, and DS recognised the need for research in this area and devised the protocol. DS recorded the data. PJ and SI carried out the drop tests. PJ, DS, and SJ wrote the manuscript. PJ is guarantor.

Funding: Self funded.

Competing interests: None declared.

Ethical approval: Not needed.

Provenance and peer review: Not commissioned; externally peer reviewed. Accepted: 21 November 2007

1 Extendicare (Canada). Osteoporosis-consumer information, 2004. www.extendicare.com

2 Nicholls C. The challenge of osteoporosis. Todays Therap issue 27 Mar/Apr, 2004.

\section{Dissent of the Testis}

We previously reported that two chocolates-Teasers and Truffles (Celebrations, Masterfoods UK, Melton Mowbray)-were strikingly similar to the $8 \mathrm{ml}$ bead of the orchidometer used to assess testicular volume. ${ }^{1} \mathrm{We}$ therefore suggested that they could be used to stage puberty in males and, because of their wide availability and low cost, commended their use.

We were recently dismayed to discover that the manufacturer has changed the shape of both these chocolates. Both are now flat bottomed (figure), and even non-specialists will notice that they bear little resemblance to testes. More disturbingly, they are no longer much use for assessing testicular volume. Only one of six paediatric endocrine specialists (comprising trainees, consultants, and specialist nurses) felt confident that they could use the new Teasers or Truffles to gauge testicular volume relative to the $8 \mathrm{ml}$ cut-off which indicates that puberty is proceeding satisfactorily. ${ }^{2}$

This is a major setback for paediatric endocrinology, and the manufacturer's decision to change the sweets' morphology without consulting the medical profession is a further kick in the Teasers. Despite conveying our concerns to the manufacturer, we have received no clear explanation, nor any reassurance that this issue is being taken seriously.

We appreciate that marketing chocolates is a matter of great commercial sensitivity and hope that we have not inadvertently hit a delicate spot by drawing attention to the fact that these sweets looked and felt like testes.
Our paper made it absolutely clear that

both Teasers and Truffles tasted better than wooden orchidometer beads ${ }^{1}$ and, we speculate, better than testes.

Clearly, the original design should be reinstated. With skilful marketing, this could play to the manufacturer's advantage: by including a simple package insert with clear, easy-to-feel instructions, young males could self evaluate their pubertal status (while pointing out that this should ideally not be done at the point of sale). This could provide a rare opportunity for the chocolate industry to become palpably involved in public health promotion.

We feel it imperative for Masterfoods to restore Teasers and Truffles to their former aesthetic and functional glory. We therefore urge readers to sign the petition at chocnuts@bris.ac.uk.

Gareth Williams Faculty of Medicine and Dentistry, University of Bristol, Bristol BS2 8DZ

Poonam Dharmaraj Department of Paediatrics, Royal Victoria Infirmary, Newcastle-upon-Tyne NE1 4 LP

Competing interests: GW's guest lecture to the Society for the Study of Ingestive Behaviour (Groningen, 2003) was sponsored by Masterfoods.

1 Bhalla P, Sally, Pippa, Williams G. An inexpensive and edible aid for the diagnosis of puberty in the male: multispecies evaluation of an alternative orchidometer. BMJ 2001;323:1486.

2 Tanner JM, Whitehouse RH. Clinical longitudinal standards for height, weight velocity and stages of puberty. Arch Dis Child 1976;51:170-9.

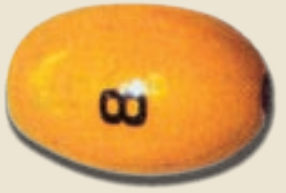

$8 \mathrm{ml}$ orchidometer bead

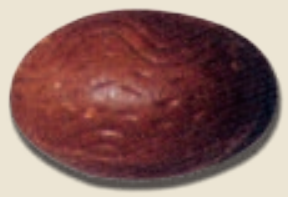

Teaser (2001)

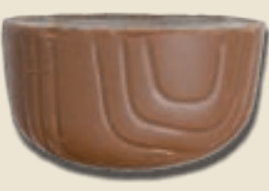

Teaser (2007) 